\title{
ANÁLISE DE POLÍTICAS PÚBLICAS E AS RELAÇÕES TRANSPARENTES DOS PODERES DA REPÚBLICA
}

\author{
PUBLIC POLICY ANALYSIS AND THE TRANSPARENT \\ RELATIONS OF THE POWERS IN REPUBLIC
}

Vicente Fonseca ${ }^{1}$

\section{RESUMO}

O tema Análise de Políticas Públicas é bastante atual e de interesse direto da sociedade brasileira. Quanto as relações transparentes dos poderes da república, estas possuem estrutura definida pela Constituição Federal de 1988. Vale a pena ressaltar que existe um sistema de controle e respeito mútuo, bem definido, conhecido no mundo jurídico como "sistema de freios e contrapesos". É importante frisar que também existe uma colaboração para, além de um controle entre os poderes, o exercício de um controle externo pelo Ministério Público e a Ordem dos Advogados do Brasil. A relação entre os poderes e as Políticas Públicas, vai além da própria estrutura constitucional, que é fortemente influenciada pelos diferentes grupos de interesses e grupos de pressão, dos quais os lobistas exercem uma influência muito importante, pois é aí que pressionam os atores dos diferentes poderes, através de linhas argumentativas, para consolidarem os seus ideais. $\mathrm{O}$ exercício do "lobby" tem notoriedade no poder Legislativo e Executivo, porém não podemos afirmar a inexistência absoluta no poder Judiciário. Fato é, todavia, que não se compara com as pressões existentes no legislativo e executivo, principalmente, porque, os membros do poder Judiciário gozam de garantias que não existem no Legislativo e Executivo. Dentro deste contexto, iremos desenvolver um estudo sobre a importância das Análises de Políticas Públicas e as relações transparentes dos poderes, para promoverem a paz e o bem-estar, para o povo brasileiro.

Palavras-chave: Relações de Poder. Lobby. Sistema de freios e contrapesos, Políticas Públicas, Grupos de interesses e Grupos de pressão.

\footnotetext{
${ }^{1}$ Centro Universitário Euro-Americano. Brasil. E-mail: vicentefonseca@hotmail.com
} 
Hegemonia - Revista Eletrônica do Centro Universitário Euro-Americano

ISSN: 1809-1261

UNIEURO, Brasília, número 30, Julho-Dezembro de 2020, p. 28-56.

\begin{abstract}
The theme of Public Policy Analysis is very current and of direct interest to Brazilian society. As for the transparent relations of the powers of the republic, these have a structure defined by the 1988 Federal Constitution. It is worth pointing out that there is a well-defined system of control and mutual respect, known in the legal world as the "system of checks and balances". It is important to stress that there is also a collaboration for, besides a control among the powers, the exercise of an external control by the Public Ministry and the Brazilian Bar Association. The relationship between the powers and Public Policies goes beyond the constitutional structure itself, which is strongly influenced by the different interest groups and pressure groups, of which lobbyists exert a very important influence, because it is there that they pressure the actors of the different powers, through argumentative lines, to consolidate their ideas. Lobbying is notorious in the Legislative and Executive branches, but we cannot say that it is absolutely nonexistent in the Judiciary. The fact is, however, that it cannot be compared to the pressures existing in the Legislative and Executive branches, mainly because the members of the Judiciary enjoy guarantees that do not exist in the Legislative and Executive branches. Within this context, we will develop a study on the importance of Public Policy Analysis and the transparent relations of the powers to promote peace and well-being for the Brazilian people.
\end{abstract}

Keywords: Power relations. Lobbying. System of checks and balances, Public Policies, Interest Groups and Pressure Groups.

\title{
INTRODUÇÃO
}

O objetivo do presente trabalho é desenvolver, inicialmente, concepções gerais acerca do processo de análise de políticas públicas e as relações de transparência com os três poderes da república federativa do Brasil: legislativo, executivo e judiciário, no jogo de interesses políticos. Serão também estudadas as diversas concepções de harmonia entre os poderes e os mecanismos que controlam a hipertrofia de um poder em detrimento de outro.

Insta salientar que, com a finalidade de englobar o trabalho em uma concepção mais ampla, estudaremos, os poderes, supramencionados, trazendo os aspectos relacionado ao Ministério Público e a Ordem dos Advogados do Brasil que, apesar de não ser propriamente um poder, são instituições que desempenham papel fundamental em uma democracia. 
Hegemonia - Revista Eletrônica do Centro Universitário Euro-Americano

ISSN: 1809-1261

UNIEURO, Brasília, número 30, Julho-Dezembro de 2020, p. 28-56.

Ao adentrar no coração do tema, relações de poder, o estudo do Lobby será abordado. Nos poderes executivo e legislativo, primordialmente, existe uma função importante exercida pelos lobistas, a fim de agilizar os projetos de lei e uma atitude ativa do executivo.

Será verificado, utilizando não apenas um método empirista, mas também dedutivo, a fim de traçar o posicionamento de doutrina autorizante acerca da temática. Isto, porque, objetiva-se deixar de lado os posicionamentos estritamente pessoais, acerca do estudo. Logo, será necessário trazer, principalmente, no estudo do lobby o funcionamento das negociações institucionais.

A Ordem dos Advogados do Brasil e o Ministério Público exercem um controle externo sobre determinados poderes e, com a capacidade postulatória tem a faculdade de acionar diversas cortes do país e do mundo. Essas atitudes influenciam, ainda que indiretamente, sobre determinada decisão de algum órgão, razão pela qual deve ser estudada.

É neste liame que, a partir da estrutura das instituições, será possível vislumbrar o que os lobistas podem influenciar no papel das políticas públicas e as diferentes instituições. As pressões exercidas através da sociedade, que inclusive, podem propor ação popular contra determinadas instituições é um sistema que inibe a atuação desta ou daquela forma dos órgãos públicos.

Destarte os poderes da república têm uma estrutura delimitada na Constituição Federal de 1988 e, a partir desta estrutura, surgem as diversas instituições a fim de auxiliar na democracia do país. A própria carta magna alocou o Ministério Público e a Advocacia, no capítulo IV, como funções essenciais à justiça. E, vale frisar, que justiça encontra-se no seu sentido amplo, ou seja, não está restrito ao poder judiciário, mais sim a uma busca por equidade na sociedade.

\section{ANÁliSE DE POLÍTICAS PÚBLICAS E AS RELAÇÕES DOS PODERES}

O estudo da lógica conceitual do processo de análise para a produção das Políticas Públicas em todas as esferas de governo é uma iniciativa de grande importância 
Hegemonia - Revista Eletrônica do Centro Universitário Euro-Americano

ISSN: 1809-1261

UNIEURO, Brasília, número 30, Julho-Dezembro de 2020, p. 28-56.

para a consolidação e aperfeiçoamento da coexistência pacífica em qualquer sociedade moderna e que tenha como meta alcançar a grandeza da nação.

Portanto, iniciaremos este artigo através da apresentação de um amplo estudo voltado para promover o conhecimento das múltiplas conceituações dos diferentes temas e procedimentos a serem adotados durante o nosso processo de aprendizado, debates e pesquisas, que serão resultantes naturais e que sem dúvida contribuirão para atingirmos um elevado grau de excelência técnica, pedagógica e científica.

No presente instante deste artigo científico, vamos inicialmente conceituar o tema em estudo e abordar as técnicas de análise para futuras Políticas Públicas. Vamos enfatizar também a formação da agenda governamental e suas soluções, para em seguida apresentar um modelo de estudo de viabilidade, que precederá o processo de elaboração. Estas ações se revestem de importância primordial para uma ótima formulação; implementação e avaliação das políticas públicas com elevado coeficiente de efetividade e equidade, para o bom desenvolvimento do nosso país.

Vale salientar que a fase de análise vai ser trabalhada nos mínimos detalhes técnico-científicos, com o fito de facilitar o entendimento dos problemas e dar qualidade e precisão ao estudo de viabilidade, que sem dúvida será um farol iluminador de todo o processo de elaboração das Políticas Públicas, no presente artigo.

Antes de passarmos ao item seguinte, procuraremos registrar que iremos mostrar de forma pragmática durante o nosso convívio que a Análise de Políticas Públicas é antes de qualquer coisa um exercício da práxis política, cujo foco principal é o de aconselhar; orientar e dar suporte as missões técnico/políticas do "policy-makers", no que tange a solução dos problemas políticos e seus fatores multiplicadores para a promoção da qualidade de vida do povo do nosso país.

Durante o Processo de Análise de Política Pública deve-se levar em conta, antes de tudo os diferentes níveis e jogos de interesse e pressão, que vão interferir em todas as fases do processo de produção de Políticas Públicas; pois vale ressaltar que a permeia todas as áreas estratégicas do governo e envolve um conjunto de decisões interligadas e interdependentes. 
Hegemonia - Revista Eletrônica do Centro Universitário Euro-Americano

ISSN: 1809-1261

UNIEURO, Brasília, número 30, Julho-Dezembro de 2020, p. 28-56.

Nesta linha de raciocínio para conseguirmos uma boa concepção da análise podemos sugerir a criação de um elenco de afirmações técnicas que vai ajudar a entender melhor o conceito de política e é por outro lado condição necessária e suficiente para o gestor desenvolver o seu trabalho, conhecendo:

- a diferença entre política e decisão: a política nasce e repousa num conjunto de interações convivendo com decisões conscientes e inconscientes dos diferentes atores sociais;

- como diferenciar política e de administração;

- que política permeia tanto intenções quanto comportamentos;

- tanto ação, como não ação;

- como pode determinar impactos inesperados;

- como os propósitos desta política podem ser ex post: racionalização;

- como a política é um conjunto de procedimentos que se consolida com o passar do tempo;

- como a política envolve as relações intra e Interorganizações;

- como a política é consolidada no espaço governamental com uma infinidade de atores.

1.1 Diferentes níveis de análise para promover a excelência das Políticas Públicas e as relações com os Poderes da República

Todo gestor de Políticas Públicas tem por obrigação saber se situar fora do jogo de interesses da política, podendo assim questionar sobre algumas questões relacionadas à máquina de governo e o aparato de Estado, que tem por obrigação apoiar a sociedade, promovendo a distribuição equânime de poder para todos os grupos sociais.

Para realizarmos uma análise adequada se faz necessário estudarmos o nível que articula as relações políticas (policy e politics).

É o nível primário e superficial das ligações e redes intra e interagências, que são determinadas pelos diferentes fluxos de recursos e de poder, em que a análise deve 
Hegemonia - Revista Eletrônica do Centro Universitário Euro-Americano

ISSN: 1809-1261

UNIEURO, Brasília, número 30, Julho-Dezembro de 2020, p. 28-56.

estar focada no processo de decisão, no interior das organizações e no processo das inter-relações. Este nível é denominado de nível de aparência ou nível superficial.

É neste nível que se manifestam os interesses imediatos no contexto administrativo:

- Primeiro são os grupos políticos atuantes no interior das instituições e que influenciam o elenco das decisões a serem adotadas;

- Segundo estão os grupos que fazem o jogo no interior de uma instituição e que geram as respostas ou demandas dos grupos externos, localizados em outras organizações públicas ou privadas. É o que podemos chamar de nível dos interesses dos atores.

1.2 Análise do processo das Relações entre o Estado e a Sociedade, no âmbito político

Tudo acontece no âmbito do conjunto estrutural do poder que determina as regras para e manter o jogo de interesses visando o equilíbrio e o consenso no que concerne o uso dos recursos. Desta forma:

Devemos observar primeiro como são determinadas as diferentes funções do Estado que asseguram a riqueza e que mantém o equilíbrio das relações entre os grupos sociais;

Segundo, devemos estudar a estrutura e o posicionamento dos diferentes níveis hierárquicos e o processo decisório da realidade do poder, que favorece o equilíbrio nas relações com a sociedade.

Terceiro, devemos analisar o papel das agências estatais que no mundo capitalista assegura todo o processo do enriquecimento e a sua legitimação diante da sociedade.

A seguir deve-se estudar as questões vinculadas a Agenda governamental, que são os problemas, entraves e impedimentos para a realização de esforços para a produção de Políticas Públicas benéficas para a nação. 
Hegemonia - Revista Eletrônica do Centro Universitário Euro-Americano

ISSN: 1809-1261

UNIEURO, Brasília, número 30, Julho-Dezembro de 2020, p. 28-56.

1.3 Análise de formação da agenda e o ciclo da política pública e as relações dos poderes

\section{a) Conceituação da Agenda}

Logo depois do estudo conceitual e procedimentos iniciais de análise das Políticas Públicas, realizado anteriormente, passamos a um assunto que é de fundamental importância para aperfeiçoarmos o nosso artigo. Pretendemos sobretudo dar profundidade e consistência a este trabalho científico, voltado para executivos de alto nível e estruturado para melhorar o entendimento de todos, com elevadíssimo grau de responsabilidade quanto a aplicação e uso das regras das Políticas Públicas no Brasil.

Assim dentro de um contexto de estudo de perspectiva do ciclo, a primeira iniciativa na direção da consolidação das ideias para Produção de uma Política Pública é o esforço para reconhecimento dos problemas, que podem evitar os conflitos entre os atores; os grupos de interesse e os grupos de pressão.

Como falei anteriormente as Políticas Públicas nascem a partir do clamor e da ansiedade do povo por dias melhores, desta forma podemos reafirmar que os problemas constituem de sobremaneira o gatilho que dá o "start" para o início do processo de criação de uma Política Pública, com elevado grau de transparência e que seja aceita por todos os poderes da República.

Portanto, é importante estudarmos todos os procedimentos do processo decisório; o comportamento dos diferentes atores; os grupos de pressão e também os grupos de interesse, para conhecermos como são gerados os problemas; de que maneira um problema bloqueia ou a agenda decisória dos diferentes governos nas diferentes instâncias da estrutura política do Brasil.

\section{b) Diferentes Denominações para as Agendas}

Vamos inicialmente trabalhar os conceitos sobre o significado de Agenda, que podemos dizer tratar-se do elenco de problemas e assuntos que formam a base de preocupação dos governos com a sua própria sustentabilidade. 
Hegemonia - Revista Eletrônica do Centro Universitário Euro-Americano

ISSN: 1809-1261

UNIEURO, Brasília, número 30, Julho-Dezembro de 2020, p. 28-56.

Por outro lado, os governos e os diferentes grupos de apoio ou de crítica concentram suas atenções sobretudo nas fraquezas do processo decisório, visando atender de forma equânime a todos.

Quanto ao processo de evolução das mudanças da agenda, ele se modifica à medida que se modificam os cenários políticos, como afirmava o Presidente Tancredo Neves: Política é como nuvens, estão em constante mudanças!

Assim podemos analisar três tipos de agenda no desenvolvimento do processo político, com vistas a enfatizar os diferentes status dos problemas no que tange uma política governamental:

- Primeiro; é na agenda governamental ou institucional que se encontram os problemas que recebem priorização no contexto do governo, não existindo ainda vertentes para estabelecer um processo decisório;

- Segundo; é na agenda não governamental ou sistêmica que encontramos o elenco de problemas de um país, provenientes do clamor do povo, mas por razões desconhecidas ainda não foram colocadas no que chamamos de "olho do governo" e sobretudo dos gestores das diferentes áreas;

- Terceiro; é na agenda política ou decisória que encontramos uma lista de problemas que estão em análise e se aprovados os gestores encaminharão para as instâncias superiores para decisão.

Os três tipos de análise apresentadas acima foi com o intuito de mostrar como são trabalhos os problemas da sociedade brasileira, facilitando assim uma melhor compreensão sobre as variáveis que influenciam o momento de decisão de uma política.

\section{c) Análise dos Diferentes Fluxos}

Com o intuito de reforçar uma melhor compreensão sobre as variáveis que influenciam o momento de decisão de uma política, como citamos no item anterior, vamos estudar a formação dos fluxos de problemas; isto quer dizer:

Como nascem e crescem os problemas que são inseridos na Agenda? Portanto, os três fluxos mais relevantes são: 
Hegemonia - Revista Eletrônica do Centro Universitário Euro-Americano

ISSN: 1809-1261

UNIEURO, Brasília, número 30, Julho-Dezembro de 2020, p. 28-56.

- Veremos em primeiro lugar o Fluxo de problemas, é o que trata de tudo que concerne a conflitos e desejos sociais e sobretudo como cada pleito deve ser atendido. Um problema é estudado e sua solução é buscada a partir da análise dos diferentes dispositivos usados no planejamento macro e microeconômico; quais sejam: a análise dos índices; a análise dos indicadores; a análise das variáveis; a análise dos dados qualitativos e quantitativos e finalmente a análise das informações, abrindo-se neste momento as discussões e negociações técnicas e políticas. Mesmo assim, o processo de tomada de decisão, só será iniciado após uma articulação com os outros fluxos.

- Veremos em segundo lugar o Fluxo de alternativas e soluções, que são as propostas feitas no dia a dia e aí estão presentes diferentes profissionais, tais como os consultores técnicos; os executivos de Relações Institucionais; os diferentes especialistas; os funcionários públicos e os grupos de interesse e de pressão.

O papel destes diferentes grupos é inicialmente o de estudar soluções e para isto trabalham na base das comunidades e a partir deste momento elaboram propostas para a solução de todos os problemas que a seguir serão apreciadas pelo processo decisório das políticas.

Dentro deste universo existe ainda os atores governamentais e não governamentais que regem o processo decisório. Por exemplo: Os atores governamentais são principalmente o Presidente da República, os Executivos de cargo de confiança, ou seja, os que tem DAS - nomeados para exercer cargos comissionados - sem concurso público e sem estabilidade, os Membros do Parlamento, Funcionários do Congresso Nacional, que são os quadros de carreira concursados; ou seja os Assessores Parlamentares.

É bom salientar que os grupos de pressão e os grupos de interesse são denominados atores não governamentais, formado por acadêmicos, por pesquisadores, pela mídia, por consultores e por diferentes partidos políticos, tendo como âncora que 
Hegemonia - Revista Eletrônica do Centro Universitário Euro-Americano

ISSN: 1809-1261

UNIEURO, Brasília, número 30, Julho-Dezembro de 2020, p. 28-56.

influencia nas decisões, a opinião pública. Os dois grupos se subdividem, em atores visíveis e invisíveis.

No que tange a atuação dos atores visíveis, esta denominação é porque eles atuam diretamente na formação da Agenda. Podemos citar como exemplo, o Presidente da República, os Parlamentares, os diferentes Partidos Políticos e a Mídia que detém o poder para atualizar as agendas governamentais.

Quanto ao que chamamos de atores invisíveis, podemos dizer que são aqueles que atuam indiretamente no processo político e participam do estabelecimento da Agenda, através de artigos científicos, novas pesquisas e estudos comparados com outros países. Estes atores invisíveis colaboram também na geração de estatísticas, mostrando novos caminhos para as novas políticas.

Assim vislumbramos a ideia de que muitos atores são influentes na formulação da agenda governamental, e outros exercem suas influências sugerindo novas alternativas para desenvolvimento político e de políticas. Neste sentido, é importante enfatizar que a elaboração de Políticas Públicas não está baseada num processo racional, onde logicamente os gestores fazem uma matriz priorizando os problemas que serão enfrentados, objetivando construir propostas e projetos com o foco na solução.

No que concerne ao Fluxo Político, veremos em terceiro lugar Fluxo político, que representa a dimensão da política, sendo neste ambiente que são promovidas a coalizões a partir de barganhas e de longas negociações.

Podemos citar assim, três elementos que exercem forte influência quanto a solução de problemas que se encontram na agenda governamental. Por exemplo:

- A personalidade dos negociadores;

- O clima político nacional;

- A expectativas de crescimento nacional e internacional; etc.

Ao encerrar o estudo destes fluxos, podemos afirmar que eles possuem vida própria com relativa independência. $\mathrm{O}$ importante é que estes fluxos estão intrinsicamente ligados a dimensões muito diferentes da operacionalidade do sistema político. 
Hegemonia - Revista Eletrônica do Centro Universitário Euro-Americano

ISSN: 1809-1261

UNIEURO, Brasília, número 30, Julho-Dezembro de 2020, p. 28-56.

\section{d) A Janela de Oportunidade (Policy Windows)}

Vale a pena enfatizar que em alguns momentos, os diferentes fluxos convergem criando 'janela de oportunidade' (policy windows), possibilitando a formação de Políticas Públicas ou mudanças nas políticas existentes.

Portanto, uma janela de oportunidade (policy Windows) apresenta um conjunto de condições favoráveis a possíveis alterações nas agendas governamental e de decisão e à entrada de novos temas nestas agendas. Assim, mostramos abaixo um esquema para ilustrar o processo de criação das 'janelas de oportunidades' (policy Windows) de autoria de Kingdon.

A Figura é um elemento facilitador para a análise, mostra de forma nítida os diferentes Fluxos do Processo de produção da Política Pública e a Janela de Oportunidade

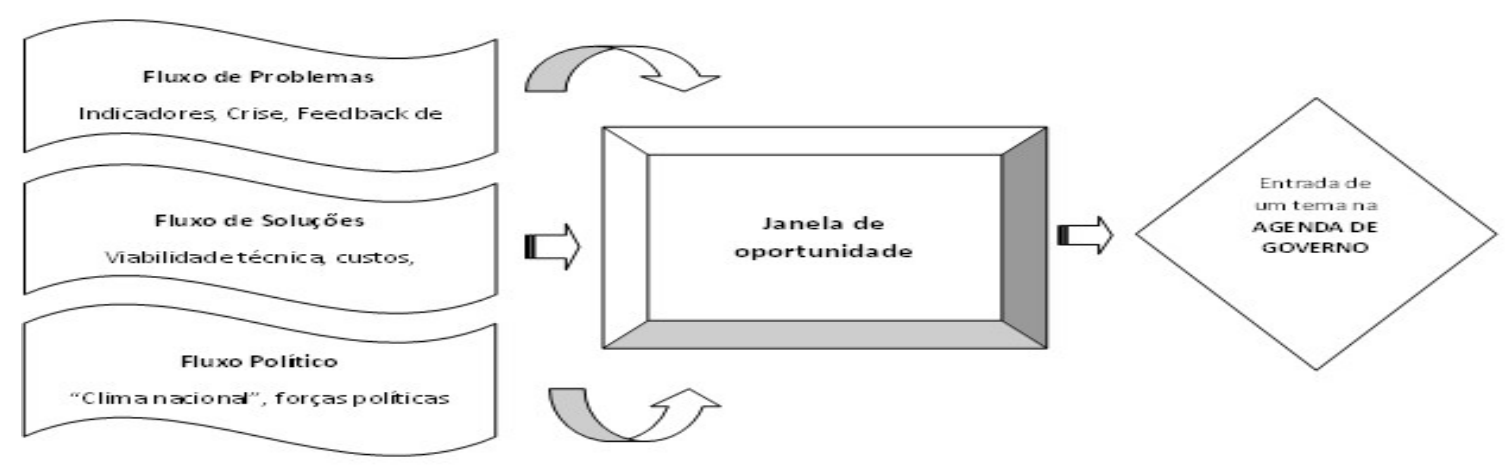

Figura 1: Os três fluxos do processo de produção da Política Pública e o processo decisório e a entrada de temas na agenda de governo. Material de aula de Políticas Públicas - Vicente Fonseca - Brasil. Inspirado em Howlett,M; Rames,M e Perl,A. - Política Pública : seus ciclos e subsistemas - Elsevier e Campus RJ - 2013, página 115.

\section{e) O Papel dos diferentes atores dos diferentes poderes}

Continuando as ideias desenvolvidas no item anterior, vamos agora buscar esclarecer e mostrar a missão dos diferentes empreendedores de política (policy 
Hegemonia - Revista Eletrônica do Centro Universitário Euro-Americano

ISSN: 1809-1261

UNIEURO, Brasília, número 30, Julho-Dezembro de 2020, p. 28-56.

entrepreneurs), estes são atores que fazem advocacy (advogam), na linguagem das Relações Institucionais; isto quer dizer, realizar propostas para ele ou para um grupo interessado em uma determinada política e este interesse pode se traduzir em grossos investimentos de recursos que podem ser traduzidos como:

- Tempo;

- Energia (Ações Humanas);

- Reputação; e

- Recursos financeiros e Econômicos.

Portanto temos aqui uma manifestação de jogo de interesses e pressão que muitas vezes afeta o processo racional para a formulação; implementação e avaliação de futuras Políticas Públicas.

É dentro desse prisma de empreendedorismo de políticas, que o nosso leitor deve prestar bem atenção para logo identificar os diferentes atores e interfaces institucionais, que surgem ao longo de um processo pragmático de negociação de produtos, que serão estudados e avaliados pelos atores dos diferentes poderes da República Brasileira.

Vamos reforçar o tema de novas oportunidades que se apresentam aos defensores de uma ação política, pois eles seguram seus problemas e propostas de soluções sempre "à mão" e quando as oportunidades surgem, logo eles entram em ação, pois eles estão constantemente em alerta e de olhos bem abertos para a janela de oportunidades, que pode abrir e se fechar muito rapidamente, sem dar tempo ao nosso "entrepreneur" agir na direção dos seus investimentos, para defender a política que sem dúvida irá beneficiar o seu grupo.

Aconselhamos ao nosso leitor que se mantenha vigilante contra as investidas dos diferentes atores, que podem prejudicar todo um processo de desenvolvimento de investimentos políticos que devem beneficiar de forma racional toda a sociedade.

Passaremos a seguir aos diferentes procedimentos para estruturar a análise de viabilidade. 
Hegemonia - Revista Eletrônica do Centro Universitário Euro-Americano

ISSN: 1809-1261

UNIEURO, Brasília, número 30, Julho-Dezembro de 2020, p. 28-56.

1.4 Metodologia científica para análise de viabilidade das políticas públicas em análise

Tomando como base os estudos realizados na unidade anterior, sobretudo no contexto de como privilegiar de forma racional a sociedade, podemos afirmar que é importante a seguir desenvolvermos um modelo de análise de viabilidade estratégica.

Nosso objetivo a ser perseguido é o de dar maior precisão a todas as iniciativas para a futura produção das Políticas Públicas, estas com uma infinidade de tarefas, que devem ser construídas, tendo como alvo a excelência.

Para tanto se faz necessário um trabalho de reflexão sobre a viabilidade do processo de decisão, que influirá de sobremaneira nos futuros passos; tais como na formulação; na implementação e na avaliação e monitoramento da Política Pública.

Voltando a nossa preocupação em apresentar um modelo adequado para uma turma de formação multidisciplinar e que deseja aperfeiçoar o seu desempenho como gestor e dirigente do Banco do Brasil, cuja missão é entender das melhores práticas para resolver as pendências dos seus clientes, apresentaremos caminhos iniciais para o bom exercício da prática da análise de viabilidade, bem como os seus diferentes domínios.

\subsubsection{Principais Tópicos para assegurar uma Análise de Viabilidade Estratégica e os Diferentes Domínios da Viabilidade Estratégica.}

Implementando a Viabilidade Política: Neste contexto os esforços estão claramente voltados para o planejamento e gestão dos diferentes recursos de poder político; com vistas aos objetivos estabelecidos anteriormente. Para que o leitor entenda melhor, podemos afirmar que se trata de produção de projetos que gerem recursos de poder político e fortaleçam o relacionamento com os todos atores. Isto significa o nosso aluno, desempenhando um importante papel político.

Implementando a Viabilidade Econômica: Neste contexto os esforços estão claramente voltados para o planejamento e gestão dos recursos no âmbito econômico e financeiro, ponto focal de trabalho para os nossos alunos, que irão com o apoio deste 
Hegemonia - Revista Eletrônica do Centro Universitário Euro-Americano

ISSN: 1809-1261

UNIEURO, Brasília, número 30, Julho-Dezembro de 2020, p. 28-56.

curso, traçar diretrizes voltadas para as operações do Banco do Brasil, produzindo iniciativas que ajustem os resultados aos recursos que estarão disponíveis, trazendo assim, segurança para todas as instâncias do processo decisório da instituição. Vale ressaltar e reafirmar que a eficácia e eficiência do ponto de vista econômico; a alta produtividade, a elevada rentabilidade; as taxas de crescimento; devem ser conduzidas como pontos prioritários. Isto significa o nosso aluno, desempenhando um importante papel de estrategista e economista.

Implementando a Viabilidade Técnica: Neste contexto os esforços estão claramente voltados para o estudo dos diferentes caminhos e regras visando melhorar a capacidade técnica operacional com vistas a planejar e gerenciar os recursos disponíveis na instituição. Isto significa o nosso aluno, desempenhando um importante papel de analista e planejador.

Implementando a Viabilidade Organizacional: Neste contexto os esforços estão claramente voltados para o estudo do potencial das capacidades institucionais; ou seja; na gestão de Recursos Humanos e os fatores multiplicadores de um processo de liderança com o objetivo de melhorar as respostas do planejamento operacional; tático e estratégico. Isto significa o nosso aluno, desempenhando um importante papel de analista de O\&M.

\section{Passos para implementar o Análise de Viabilidade}

Os pontos anteriores que compõem esta unidade servem de balizas para se chegar a um consenso sobre qual a melhor forma para viabilizar projetos que se tornarão Políticas Públicas. Então, sugerimos a adoção inicial da técnica de Planejamento por Cenários de comprovada eficácia e eficiência, para dar suporte ao processo decisório que indicará se realmente o que se está pensando é viável.

No Planejamento por Cenários o que mais importa é a reflexão diagnóstica.

1. Quais são os componentes da reflexão diagnostica?

Análise da Situação, Síntese do Problema e Critica.

2. Quais são as características do Planejamento por Cenários?

- O planejamento por cenários é feito (se analisa) de fora da instituição para dentro; 
Hegemonia - Revista Eletrônica do Centro Universitário Euro-Americano

ISSN: 1809-1261

UNIEURO, Brasília, número 30, Julho-Dezembro de 2020, p. 28-56.

- Desenvolve-se um esforço para reconhecer os elementos externos que ameaçam ou favorecem.

3.Quais são os múltiplos cenários a serem planejados?

- Cenário otimista;

- Cenário realista;

- Cenário pessimista.

A partir daí se realiza um posicionamento.

4- Quais são as táticas que devemos usar p/ consolidar a motivação de todos envolvidos neste processo?

- Alinhar as ideias políticas $\mathrm{p} /$ promover a satisfação máxima da sociedade;

- Aperfeiçoar a comunicação com os diferentes atores;

- Preparar eficazmente os funcionários;

- Transformar ideias em ações;

- Envolver todo o staff no processo decisório;

- Criar um quadro mental de disciplina de valores.

Os 10 maiores pecados capitais no processo de construção de estratégias para a Análise de Viabilidade

1. Desconhecer as técnicas de acompanhamento, avaliação e controle de projetos;

2. Agir sem levar em consideração os valores estratégicos do projeto;

3. Não inserir no estudo possíveis oscilações econômicas e financeiras;

4. Não saber quando interferir num processo de Planejamento e Gestão;

5. Não levar em consideração as técnicas de posicionamento político das lideranças;

6. Não decidir no momento certo para a tomada de decisões;

7. "Não realizar o Balanço da Situação - Curva Crescente Física / Financeira; 
Hegemonia - Revista Eletrônica do Centro Universitário Euro-Americano

ISSN: 1809-1261

UNIEURO, Brasília, número 30, Julho-Dezembro de 2020, p. 28-56.

8. Não promover a avaliação desempenho de RH - "Matriz de Responsabilidade"

9. Não promover um balanço da base de apoio político;

10. Não saber acompanhar o crescimento e estabilidade do uso correto dos recursos.

Qual a importância de se evitar os 10 pecados capitais no processo?

A importância maior está ligada ao bom desempenho da Análise de Viabilidade, onde todos estes elementos estão intrinsecamente ligados e uma falha qualquer pode desestabilizar o sistema de sobrevivência de um projeto de Política Pública.

\subsubsection{Diferentes dimensões que devem ser levadas em consideração no processo de} Análise de Viabilidade:

Como falamos no item anterior sobre os cenários, agora vamos mostrar a importância de se levar em consideração as 4 dimensões que devemos atuar para que a análise de viabilidade aponte na direção correta objetivando o sucesso da Política Pública,

Dimensão 1 - Análise das perspectivas dos diferentes atores envolvidos no projeto de Política Pública.

Dimensão 2 - Análise dos objetivos políticos internos e compará-los com os externos.

Dimensão 3 - Análise de perspectiva da inovação e da aprendizagem organizacional.

Dimensão 4 - Análise da perspectiva financeira.

A seguir o gestor deve realizar um estudo para respaldar sua análise externa fundamentada nas seguintes perguntas:

- Quais são as tendências e as possíveis mutações futuras?

- Quais são as ameaças e oportunidades a curto e médio prazo? 
Hegemonia - Revista Eletrônica do Centro Universitário Euro-Americano

ISSN: 1809-1261

UNIEURO, Brasília, número 30, Julho-Dezembro de 2020, p. 28-56.

- Quais são as áreas-chaves de incerteza com referência as tendências que podem trazer impactos negativos ao nosso projeto?

- É possível avaliar essas incertezas em termos de impacto ao nosso planejamento?

- Que incertezas são válidas como base para avaliação de cenários futuros?

Além disso, nós temos que levar em consideração os seguintes aspectos:

- Possíveis mudanças de comportamento da sociedade;

- Possíveis mudanças de padrão de vida da sociedade, com o advento da Política Pública;

- Oscilações econômicas;

\subsubsection{Relatório de Avaliação da Viabilidade da Política Pública em processo de análise para facilitar as relações dos poderes da república}

Como se deve fazer um relatório para construir na prática novos cenários, cujo objetivo é a avaliação da viabilidade da futura Política Pública transparente e facilitadora das relações dos diferentes poderes da república?

Através dos seguintes estudos:

- A situação atual de estabilidade e consenso no sistema político e as relações dos poderes da república;

- O nível das decisões tomadas a curto, médio e longo prazo, e seus impactos para a sociedade;

- As tendências futuras do sistema político;

- Planejamento de investimentos a serem realizados;

- As vantagens do empreendimento da Política Pública em relação aos desafios para estabelecer excelentes relações dos poderes da república;

- As oportunidades futuras para todos, com o advento da Política Pública;

- A situação da região a ser beneficiada;

- Planejamento da alocação de recursos materiais humanos e financeiros; 
Hegemonia - Revista Eletrônica do Centro Universitário Euro-Americano

ISSN: 1809-1261

UNIEURO, Brasília, número 30, Julho-Dezembro de 2020, p. 28-56.

- Os resultados esperados a curto, médio e longo prazo, e seus impactos para a sociedade;

- O Projeto é viável?

- Sugestões e relatórios finais.

\section{ESTRUTURA DOS PODERES DA REPÚBLICA NA PERSPECTIVA DAS RELAÇÕES DE PODERES E AS POLÍTICAS PÚBLICAS}

A Constituição Federal de 1988 estruturou os poderes da república de maneira analítica ao longo da carta fundamental. $\mathrm{O}$ artigo $2^{\circ}$ da Constituição da República já definiu que os poderes deveriam atuar de maneira harmônica, sem retirar, por óbvio, a independência que lhe é assegurada e necessária para desempenhar suas atribuições. ${ }^{2}$

A Constituição Federal, com o fito de evitar o arbítrio e o desrespeito aos direitos fundamentais do homem, traçou a existência dos poderes do Estado Democrático, harmônicos e independentes, com políticas públicas transparentes e uteis para a sociedade brasileira. O texto constitucional, inclusive, traçou a repartição de competências e criou mecanismos de controle recíprocos, a fim de garantir a perpetuidade do Estado Democrático de Direito (Moraes, 2006, p. 383).

Alexandre de Moraes acrescenta:

A divisão segundo o critério funcional é a célebre "separação de Poderes", que consiste em distinguir três funções estatais, quais sejam, legislativo, administração e jurisdição, que devem ser atribuídas a três órgãos autônomos entre si, que as exercerão com exclusividade, foi esboçada pela primeira vez por Aristóteles, na obra "Política", detalhada, posteriormente, por Jophn Locke, no Segundo tratado do governo civil, que também reconheceu três funções distintas, entre elas a executiva, consistente em aplicar a força pública no interno, para assegurar a ordem e o direito, e a federativa, consistente em manter relações com outros Estados, especialmente por meio de alianças. E, finalmente, consagrada na obra de Montesquieu $O$ espirito das leis, a quem devemos a divisão e tributação clássicas, tornando-se princípio fundamental da organização política liberal e transformando-se em dogma pelo art. 16 da Declaração Francesa dos Direitos do Homem e do Cidadão, de 1789, e é prevista no art. $2^{\circ}$ da nossa Constituição Federal (2006, p. 387).

\footnotetext{
${ }^{2}$ Art. $2^{o}$ da CF: São poderes da União, independentes e harmônicos entre si, o Legislativo, o Executivo e o Judiciário
} 
Hegemonia - Revista Eletrônica do Centro Universitário Euro-Americano

ISSN: 1809-1261

UNIEURO, Brasília, número 30, Julho-Dezembro de 2020, p. 28-56.

Torna-se necessário, para o desempenho do exercício das funções estatais, imunidade e garantias previstas para os membros dos três poderes da república. Ainda que exista certa polémica acerca de determinadas garantias aos agentes políticos, deve-se ater que todos os poderes têm prerrogativas similares, haja vista a obtenção da igualdade entre os poderes: Legislativo, Executivo e Judiciário.

A União, fazendo as vezes de entidade direito público interno, possui órgãos próprios e uma divisão política esculpida na divisão de poderes. O Sistema de Governo consiste em uma técnica que verifica a relação entre o legislativo e o executivo. A forma como eles se relaciona dá origem a três sistemas básicos de governo: presidencial, parlamentar e convencional. No Brasil adota-se o sistema de governo presidencialista, haja vista a maior independência entre os poderes (SILVA, 2006, p. 505).

O presidencialismo, sistema adotado no Brasil, é típico das repúblicas. Neste sistema o presidente da república exerce a função de chefe de Estado e chefe de Governo, ou seja, exerce o poder executivo em toda sua inteireza. O presidente da república cumpre um mandato por tempo fixo, não dependendo da confiança do poder legislativo. A relação entre esses poderes é mais rígida prevalecendo a independência e divisão de funções (SILVA, 2006, p. 505-506).

O parlamentarismo, sistema não adotado no Brasil, consiste num sistema típico das monarquias. Nele, o poder executivo se divide em duas partes, pois, o chefe de Estado representa o país, primordialmente nas relações exteriores e o primeiro-ministro representa o país internamente, existindo uma maior dependência, nesse sistema de governo, entre o executivo e o legislativo (SILVA, 2006, p. 506).

Insta salientar que na atualidade existe, primordialmente, dois sistemas de governo que predominam no mundo: presidencialismo e parlamentarismo. Todavia, vale traçar algumas considerações acerca do sistema de governo convencional, também conhecido como assembleia (SILVA, 2006, p. 505).

No sistema convencional (de assembleia) não existe um executivo que se separa do parlamento. Não existe um governo separado, pois, a direção do país é exercida por uma comissão na Assembléia. Caso, eventualmente, existe um chefe do executivo, este, 
Hegemonia - Revista Eletrônica do Centro Universitário Euro-Americano

ISSN: 1809-1261

UNIEURO, Brasília, número 30, Julho-Dezembro de 2020, p. 28-56.

é visto como uma figura decorativa. Os exemplos são da Suíça, Polônia, Hungria, Roménia e Bulgária (SILVA, 2006, p. 505).

O Poder Legislativo brasileiro possui, como função típica legislar e fiscalizar. Muito embora a carta fundamental estatui as regras do processo legislativo para elaboração de normas jurídicas, não se pode esquecer a disposição do artigo 70 da Constituição Federal de 1988 que traz a fiscalização contábil, orçamentaria, financeira, operacional e patrimonial do Poder Executivo. (MORAES, 2006, p. 389). ${ }^{3}$

Vale frisar que, apesar das funções típicas, o legislativo exerce funções atípicas, consistente em administrar e julgar. A primeira ocorre, por exemplo, quando o Poder Legislativo exerce sua organização interna. A segunda pode ser visualizada quando o Poder Legislativo julga o presidente da república por crime de responsabilidade. (MORAES, 2006, p. 389).

O Poder Executivo, da mesma forma exerce funções típicas e atípicas. A função típica e notória é que o executivo administra a coisa pública. Como função atípica podemos identificar uma função legislativa na edição de medida provisória e uma função judiciária quando julga os processos administrativos disciplinares dos servidores vinculados.

Insta salientar, nas lições de Alexandre de Moraes, acerca da estrutura do Poder Executivo, o seguinte:

Na estrutura do Poder Executivo verifica-se a existência de duas funções primordiais diversas, quais sejam, a de Chefe de Estado e de Chefe de Governo.

\section{(...)}

Assim, como chefe de Estado, o presidente representa, pois, nas suas relações internacionais (art. 84, VII e VIII, XIX), bem como corporifica, a unidade interna do Estado.

Como chefe de Governo, a função presidencial corresponde à representação interna, na gerência dos negócios internos, tanto os de natureza política (participação no processo legislativo), como nos de natureza eminentemente administrativa (art. 84, I, II, III, IV, V, VI, IX a XXVII). Assim, o Chefe do Governo exercerá a liderança da política nacional, pela orientação das decisões gerais e pela direção da máquina administrativa (MORAES, 2006, p. 441-442).

\footnotetext{
${ }^{3}$ Artigo 70 da Constituição Federal de 1988: "A fiscalização contábil, financeira, orçamentária, operacional e patrimonial da União e das entidades da administração direta e indireta, quanto à legalidade, legitimidade, economicidade, aplicação das subvenções e renúncia de receitas, será exercida pelo Congresso Nacional, mediante controle externo, e pelo sistema de controle interno de cada Poder".
} 
Hegemonia - Revista Eletrônica do Centro Universitário Euro-Americano

ISSN: 1809-1261

UNIEURO, Brasília, número 30, Julho-Dezembro de 2020, p. 28-56.

O Poder Judiciário tem como função típica julgar os conflitos existentes na sociedade. O Poder Judiciário aplica a lei a um caso concreto. Entretanto, este poder possui como função atípica a possibilidade de organizar-se internamente e legislar, na medida que tem competência para elaborar seu regimento interno.

A teoria da tripartição de poderes vem sendo estudada e argumentada por vários autores, desde a idade média. A paternidade da teoria foi atribuída a Aristóteles em sua obra "A Política", porém o maior grau de sistematização ocorreu, em verdade, com Montesquieu (AUGUSTO; DOURADO; ROSE, p. 2638).

Neste sentido, vale ressaltar:

O grande autor francês Charles-louis de Secondat, mais conhecido como Montesquieu, tinha como principal objetivo a salvaguarda da liberdade individual ao escrever sua famosa obra 'O Espírito das Leis'. Em tal obra, o autor propunha para este fim a separação dos poderes que se identifica como o princípio constitucional de maior importância de todo o período liberalista (AUGUSTO; DOURADO; ROSE, p. 2638).

Neste liame, a reflexão de Montesquieu consistia na ideia de liberdade. Acepção de liberdade deveria consistir na possibilidade de se fazer o que é permitido pela norma posta. Partindo dessa premissa o pensador parte do pressuposto que existe uma tendência de arbitrariedade a aqueles que detém o poder em suas mãos, impedindo a liberdade, portanto foi necessária uma organização da sociedade, para que um poder possa intervir no outro concomitantemente. (AUGUSTO; DOURADO; ROSE, p. 2638).

Destarte que a estrutura de poder se necessita de uma intervenção de maneira recíproca no outro, fazendo com que os direitos e liberdades possam ser observados, evitando, com isso, a arbitrariedade do detentor do poder. A Constituição da República Federativa do Brasil de 1988 concordou com Montesquieu, adotando a conhecida denominação do mundo jurídico de "divisão orgânica de Montesquieu".

2.1 A prática da análise e da implementação das políticas públicas e as incertezas das relações dos poderes da República Brasileira

A prática da análise e da implementação das políticas públicas são temas muito criticados no Brasil. A sociedade encontra-se descontente com os rumos da política no 
Hegemonia - Revista Eletrônica do Centro Universitário Euro-Americano

ISSN: 1809-1261

UNIEURO, Brasília, número 30, Julho-Dezembro de 2020, p. 28-56.

país. Esse fato tem sido comumente associado de uma maneira negativa ao termo "lobista". Comumente, o termo, tem sido criticado e visto como algo imoral ou ilegal, razão pela qual analisaremos o termo.

Nesta linha, vale citar a jornalista Rose Maria Vidal de Souza:

Lóbi (também grafado lobby) ou grupo de pressão é um grupo de pessoas ou organização que tem como atividade buscar influenciar, aberta ou secretamente, decisões do poder público, especialmente do poder legislativo, em favor de determinados interesses privados. Pressões e manipulações exercidas por lobbies também são observadas em outras instâncias do poder público (Executivo, Judiciário), e também sobre meios de comunicação. (SOUZA: p. 2).

Vale ressaltar que fazer lobby é algo muito natural, feito no cotidiano. Vale citar, a título de exemplo, o argumento de convencimento quando um filho tenta convencer o pai a comprar um vídeo game. (SOUZA, p. 2-3).

O Lobby existe em todos os poderes da república. Todavia, tem maior repercussão e notoriedade nos poderes legislativo e executivo. O poder judiciário, que consiste num poder que aplica a lei ao caso concreto, não sofre influenciar externas de lobistas como o executivo e legislativo. Um fator que limita essa intervenção é a vitaliciedade dos membros daquele poder, que não existe no legislativo e executivo. $\mathrm{O}$ poder judiciário até pode sofrer pressões externas, por exemplo, da mídia. Ocorre que não podemos compará-la as intervenções do legislativo e executivo.

Vale ressaltar, outrossim, que o lobby só existe em uma democracia, são atividades necessárias e lícitas. Isso fortalece a democracia e, apesar de não ser regulamentado, seria de grande valia sua regulamentação no Brasil (SOUZA, p. 3).

As atividades de lobismo são esclarecidas por Souza, citando Graziano:

A atividade inclui a coleta de informações, propostas políticas, estratégias apropriadas para dar suporte a tais demandas, confecção de pesquisas e a procura de aliados. O lobbyng proporciona a troca de informações e de ideias entre governo e partes privadas, capazes de infundir nas políticas públicas conhecimento de causa e realismo consciente. Seu último estágio é a pressão, momento em que o lobista deve se valer de seu poder de comunicação de persuasão. Sendo assim, podemos conceber o lobbyng como saber especializado e representação técnica, pois enquanto representam interesses especiais, os lobistas são o sustentáculo da informação de um especialista técnico-político (GRAZIANO, 1994 apud SOUZA: p. 2). 
Hegemonia - Revista Eletrônica do Centro Universitário Euro-Americano

ISSN: 1809-1261

UNIEURO, Brasília, número 30, Julho-Dezembro de 2020, p. 28-56.

Dessa forma, não podemos visualizar o lobby como algo negativo e ilegal. Principalmente, porque, como já foi dito, é algo que ocorre no cotidiano na sociedade. Uma linha argumentativa como o fito de atingir um fim pode ser, em apertada síntese, configurado como lobby. Apesar de não ser regulamentado no Brasil não é ilegal.

2.2 Mecanismos que viabilizam as relações de poder e as formas de intervenção de um poder sobre outro.

A concepção contemporânea da teoria da divisão de poderes foi formada ao longo da história e reflete diversas mutações políticas, econômicas e sociais. (ALVES, p.2).

Segundo Bruno Franco Alves:

Já na obra de Aristóteles podem ser encontrados elementos que identificam a existência de funções estatais distintas e alertam para os perigos do exercício do poder por um só indivíduo. Todavia é no processo de concretização do Estado Moderno que os contornos dessa teoria são definidos, sendo que as obras Defensor Pacis, de Marcílio de Pádua, O Príncipe, de Maquiavel, e Segundo Tratado sobre o Governo Civil, de John Locke, são exemplos importantes da contribuição teórica desse período.

Essas obras manifestaram perspectivas diferentes sobre a temática, destacando-se o fato de ter sido Locke o primeiro a apresentar de maneira sistematizada quais seriam as funções estatais e os órgãos responsáveis por exercê-las (ALVES, p. 2).

Muito embora existisse a contribuição de vários pensadores, a paternidade da teoria da divisão de poderes deve ser conferida a Montesquieu. Esse modelo, consagrado, está positivado em vários diplomas, os quais podemos citar: Constituição dos Estados Unidos e a Declaração dos Direitos do Homem e do Cidadão (ALVES, p. 3).

No Brasil, o sistema pode ser visualizado no artigo $2^{\circ}$ da Constituição Federal, que afirma a independência dos poderes e sua harmonia. Vale frisar que o artigo é tão importante que é considerado cláusula pétrea da Constituição Federal de 1988. Ou seja, 
Hegemonia - Revista Eletrônica do Centro Universitário Euro-Americano

ISSN: 1809-1261

UNIEURO, Brasília, número 30, Julho-Dezembro de 2020, p. 28-56.

trata-se de um artigo que não pode ser modificado por emenda à constituição. É o teor do artigo $60 \S 4^{\circ}, \mathrm{III}, \mathrm{CF} / 88 .^{4}$

O modelo adotado é harmônico e independente, mas, para uma harmonia verdadeira, um não pode influenciar de maneira drástica no outro, porém, não pode, todavia, não ter influência, ainda que de maneira mínima. Existe um mecanismo comumente consagrado no mundo jurídico: sistema de freios e contrapesos. Significa que um poder influencia na outro, apesar de independente.

Vale frisar, por exemplo, que no Brasil o executivo escolhe os ministros do Supremo Tribunal Federal, todavia, esses ministros são sabatinados pelo poder legislativo, devendo ser aprovados por um quórum específico. Ou seja, nota-se a influência do executivo e legislativo na escolha dos ministros do Supremo. Da mesma forma existe um controle em cima do executivo, pois, o executivo, na figura do presidente da república, pode ser afastado por um julgamento pelo Poder Legislativo e, conduzido pelo presidente do Supremo. Nota-se, outrossim, a interferência destes poderes no Executivo. O Poder Legislativo, por sinal, também tem um controle, porque, suas normas podem ser vetadas pelo presidente da república, bem como ser declaradas inconstitucional pelo Poder Judiciário. Logo, resta demonstrada o sistema de freios e contrapesos.

O mecanismo evita a hipertrofia de um poder sobre o outro, razão pela qual devem trabalhar em harmonia constante, para bem do povo. A máquina pública, inclusive, por presumir a busca do bem coletivo tem diversos princípios para poder atuar incisivamente, como o princípio da supremacia do interesse público sobre o privado, conhecido como um dos princípios norteadores da atividade administrativa.

A divisão orgânica de Montesquieu sofre algumas críticas. Bruno Franco Alves, citando Dallari, argumenta:

Entretanto, esse esquema tradicional de divisão de Poderes não está imune a críticas. Dallari afirma que o modelo é 'meramente formalista, jamais tendo sido praticado'. Isso porque, na visão do autor, mesmo nas constituições que consagram enfaticamente o princípio da divisão de poderes, a prática revela a existência de uma intensa interpretação destes. Além disso, existem fatores extralegais que acabam por determinar a preponderância de um dos Poderes sobre os demais (DALLARI, 1995 apud ALVES, p. 3).

\footnotetext{
${ }^{4}$ Art. $60 \S 4^{\circ}$ : Não será objeto de deliberação a proposta de emenda tendente a abolir; III: A separação dos poderes.
} 
Hegemonia - Revista Eletrônica do Centro Universitário Euro-Americano

ISSN: 1809-1261

UNIEURO, Brasília, número 30, Julho-Dezembro de 2020, p. 28-56.

Assim, apesar de existir críticas acerca do sistema parece que é um dos mais sólidos até o momento, tanto que é adotado por vários países, inclusive os Estados Unidos da América. Neste interim, apesar da visão do autor, supramencionado, existir a hipertrofia de algum dos poderes eventualmente, o sistema, ainda assim, é louvável.

2.4 Ministério Público e Ordem dos Advogados do Brasil: controle dos Poderes da República e das Políticas Públicas

Muitas vezes o processo de Análise de Políticas Públicas é falho, por conta do jogo de interesses que existe na política, sendo imediatamente criticado em todo o Brasil. Porém existem, todavia, mecanismos e instituições que podem, com auxílio da sociedade, controlar estas falhas e as reações dos poderes da república. O Ministério Público e a Ordem dos Advogados do Brasil são instituições ímpares para a defesa da democracia e do estado democrático de direito.

O Ministério Público, segundo Pedro Lenza, pode ser definido da seguinte forma:

De acordo com o art. 127, caput, da CF/88, o Ministério Público é instituição permanente, essencial à função jurisdicional do Estado, incumbindo-lhe a defesa da ordem jurídica, do regime democrático e dos interesses sociais e individuais indisponíveis (LENZA, 2012, p. 840).

O Ministério Público é subdividido em Ministério Público Estadual e Ministério Público da União. Este é subdividido em Ministério Público Federal, Ministério Público do Trabalho, Ministério Público Militar e Ministério Público do Distrito Federal e Territórios (LENZA, 2012: p. 841).

Vale ressaltar, outrossim, que o Ministério Público possui princípios institucionais: unidade, indivisibilidade e independência funcional. O princípio da unidade significa que o Ministério Público deve ser visto como uma instituição única e as divisões existentes são meramente funcionais. O princípio da indivisibilidade, que está umbilicalmente ligado ao princípio da unidade, quer dizer que um membro do Ministério Público pode substituir outro, pois quem exerce os atos é o "Ministério Público". O 
Hegemonia - Revista Eletrônica do Centro Universitário Euro-Americano

ISSN: 1809-1261

UNIEURO, Brasília, número 30, Julho-Dezembro de 2020, p. 28-56.

princípio da independência funcional significa que os membros do Ministério Público não se submetem a qualquer poder hierárquico (LENZA, 2012: p. 848).

Para que o Ministério Público possa agir com imparcialidade, na busca de seu mister, é necessário garantias institucionais: autonomia funcional, autonomia administrativa e autonomia financeira. A autonomia funcional significa que o membro do Ministério Público não se submete a nenhum outro poder, conforme consta no artigo $127 \S 2^{\circ}$ da $\mathrm{CF} / 88$. A autonomia administrativa diz respeito a capacidade de direção de si próprio. A autonomia financeira, que tem fulcro no artigo $127 \S 3^{\circ}$ da $\mathrm{CF} / 88$, consiste na capacidade de elaborar sua proposta orçamentária, administrando seus recursos, desde que no limite da lei de diretrizes orçamentarias (LENZA, 2012: p. 855).

O Ministério Público possui várias funções, esculpidas no artigo 129 da Constituição Federal e consiste numa instituição essencial na defesa do estado democrático de direito. Dentre as várias funções do Ministério Público, vale ressaltar que esta instituição tem o monopólio da ação penal pública, que consiste numa grande arma na defesa do estado democrático. A instituição tem uma importância significativa no controle externo dos poderes da república: executivo, legislativo e judiciário.

A outra instituição que merece destaque é a Ordem dos Advogados do Brasil. Nas lições de Pedro Lenza, acerca da OAB, podemos destacar:

$\mathrm{O}$ art. 133 da $\mathrm{CF} / 88$ dispõe que o advogado é indispensável à administração da justiça, sendo inviolável por seus atos e manifestações no exercício da profissão, nos limites da lei (LENZA, 2012: p. 840).

A Ordem dos Advogados do Brasil é uma instituição que tem um quantitativo de pessoal elevado. Isso possibilita que os advogados possam estar em diversas áreas da sociedade. Esse numerário não se compara a nenhuma outra instituição. Apesar de não significar que os advogados estejam em todo momento atuando no controle externo dos poderes da república, sua presença é um fator inibidor.

O processo de impeachment da presidente da república Dilma Rousseff, por exemplo, adveio de uma petição subscrita por advogados. Esse fato, por si só, demonstra a importância do advogado, bem como a possibilidade de atuar em diversas esferas como forma de controle dos poderes da república. O advogado, por ter capacidade postulatória, 
Hegemonia - Revista Eletrônica do Centro Universitário Euro-Americano

ISSN: 1809-1261

UNIEURO, Brasília, número 30, Julho-Dezembro de 2020, p. 28-56.

pode acionar diversos órgão, inclusive em causa própria. Ele pode, ainda, propor ação popular para anular ato lesivo ao patrimônio público, sem necessitar de autorizar de qualquer instituição.

Destarte que a Ordem dos Advogados do Brasil e o Ministério Público são instituições importantes na defesa do estado democrático de direito e grandes colaboradores com o controle do jogo de interesses embutidos nas políticas públicas e na prática dos poderes da República Federativa do Brasil.

\section{CONCLUSÃO}

Os diferentes grupos de atores ligados a análise de políticas públicas e no exercício das instituições que compõem os 3 Poderes da República, por expressa disposição constitucional, devem trabalhar em harmonia e conjuntamente.

Apesar de existir uma harmonia, o controle de um poder sobre o outro não deve ser esquecido. A Constituição de 1988 traz uma estrutura que, além de traçar a divisão de competências, permite que um poder controle o outro. Esse sistema de controle é conhecido e consagrado no mundo jurídico, como sistema de freios e contrapesos.

No Brasil adota-se o sistema de governo utilizado em vários países do mundo: sistema de governo presidencialista. Esse sistema ou regime de governo permite que o presidente da república exerça a direção do país interna e externamente, diferente do sistema de governo parlamentarista. No parlamentarismo o presidente da república exerce a função de Chefe de Estado enquanto o primeiro-ministro exerce a função de chefe de governo. Nesse sistema existe uma maior relação e dependência entre o executivo e legislativo.

Os poderes da República no Brasil, apesar de ter funções bem distintas, não significa que sua competência seja extremamente rígida. Os poderes, muito embora tenha suas funções típicas, possuem funções atípicas que, seriam de competência de outro poder.

A prática da Política e da Política Pública, vem sendo criticada pelos brasileiros e, de maneira errônea, o termo "lobby" tem sido associada a uma prática imoral, ilegal e 
Hegemonia - Revista Eletrônica do Centro Universitário Euro-Americano

ISSN: 1809-1261

UNIEURO, Brasília, número 30, Julho-Dezembro de 2020, p. 28-56.

negativa. Entretanto, o termo nada mais é do que uma linha argumentativa que objetiva o convencimento de algo. Consiste numa forma de buscar, pressionar e argumentar acerca de uma tomada de decisão ou uma postura de algum dos poderes da república.

Os poderes que têm uma maior pressão externa são o Legislativo e Executivo. Vale ressaltar que não podemos excluir e afirmar a inexistência de pressão externa e de lobistas no Poder Judiciário, mas, podemos ressaltar que não se compara aquelas existentes no Executivo e Legislativo. Um fator importante é que os membros do poder Judiciário possuem vitaliciedade, ao contrário dos membros do executivo e legislativo, que necessitam de uma aceitação da sociedade.

Os mecanismos que viabilizam as relações entre os poderes são determinados pela própria Constituição Federal, pois os poderes têm e sofre influência dos outros. Basta citar, por exemplo, que o Poder Judiciário, na sua mais alta corte (Supremo Tribunal Federal), tem seus membros indicados pelo Presidente da República (executivo) e necessita de uma aprovação, por maioria absoluta, pelo Senado Federal (legislativo) para, só então, ser nomeado para ministro do Supremo Tribunal Federal. Nota-se a presença dos poderes influenciando e controlando-os entre si.

Insta salientar que, apesar da existência de controle entre os poderes da república, o Ministério Público e a Ordem dos Advogados do Brasil, são instituições que colaboram com o controle externo dos poderes da república. As instituições possuem capacidade postulatória para questões específicas, que podem ser grandes instrumentos de controle.

Destarte que a Constituição Federal de 1988 adotou a divisão orgânica de Montesquieu e os poderes da república, a partir dessa divisão, possui um sistema composto por diversas regras que são pedras nortes para uma democracia. Aliada a esta divisão, outras instituições, como o Ministério Público e a Ordem dos Advogados do Brasil, auxiliam na preservação da democracia no Brasil.

\section{REFERÊNCIAS}

ALVES, Bruno Franco. A relação entre os Poderes no Brasil: uma análise da atividade legislativa do Poder Executivo à luz da teoria democrática. Disponível em: 
Hegemonia - Revista Eletrônica do Centro Universitário Euro-Americano

ISSN: 1809-1261

UNIEURO, Brasília, número 30, Julho-Dezembro de 2020, p. 28-56.

$<$ https://www.almg.gov.br/opencms/export/sites/default/consulte/publicacoes_assemblei a/obras_referencia/arquivos/pdfs/legistica/relacao_poderes.pdf $>$

AUGUSTO, Natália Figueiroa; DOURADO, Edvânia A. Nogueira; ROSA, Crishna Mirella de Andrade Correa. Dos Três Poderes de Montesquieu à Atualidade e a Interferência do Poder Executivo no Legislativo no Âmbito Brasileiro. Congresso Internacional de História. Disponível em: $<$ http://www.cih.uem.br/anais/2011/trabalhos/213.pdf $>$. Acessado em: 19 de julho de 2016.

HOWlett, M; RAMES, M e PERL, A. Política Pública: seus ciclos e subsistemas Elsevier e Campus - RJ-2013, página 115.

LENZA, Pedro. Direito Constitucional Esquematizado. 16ª Edição. São Paulo: Saraiva, 2012.

MORAES, Alexandre de. Direito Constitucional. 20ª Edição. São Paulo: Atlas, 2006.

RUEL, Thiago Santos. Lobby, Grupos de Pressão e Grupos de Interesses. Disponível em: <http://www.craes.org.br/arquivo/artigo Técnico/Lobby_28.pdf > . Acessado em 19 de julho de 2016.

SILVA, José Afonso da. Curso de Direito Constitucional Positivo. 26 ${ }^{\text {a }}$ Edição. São Paulo: Malheiros, 2006.

SOUZA, Rose Mara Viudal de. Lobby no Brasil regulamentado e a democracia participativa. Disponível em: <http://www.compolitica.org/home/wpcontent/uploads/2011/01/rose_vidal.pdf>

Recebido em: 08.04.2020

Avaliado em: 20.06.2020

Aprovado em: 23.07.2020 